\title{
Infantile Myofibroma: Case Report and Review of the Literature
}

\author{
Azusa Ogita and Shin-ichi Ansai
}

\begin{abstract}
Department of Dermatology and Dermatopathology, Nippon Medical School Musashi Kosugi Hospital, Kanagawa, Japan We report a case of solitary infantile myofibroma (IM) with partially CD34-positive neoplastic cells on the back of a newborn boy. Ultrasonography showed a multilocular mass with a hypoechoic center surrounded by an isoechoic rim. Histopathological analysis revealed that the lesion was composed of small, round cells that were tightly packed and uniform. The cells had oval nuclei and were pale, CD34-positive, and richly cellular. They had interlacing fascicles of spindle cells with features of myofibroblasts with $\alpha$-smooth muscle actin positivity. We speculate that neoplastic cells in most IMs differentiate towards myofibroblasts. However, in rare cases, their differentiation is more primitive and they express CD34, with or without $\alpha$-smooth muscle actin expression. (J Nippon Med Sch 2020; 87: 355-358)
\end{abstract}

Key words: infantile myofibroma, CD34, solitary, infantile hemangiopericytoma

\section{Introduction}

Myofibroma and myofibromatosis are benign neoplasms of presumed myofibroblastic histogenesis and phenotype $^{1}$. The $90 \%$ of cases that occur in children are designated infantile myofibroma (IM), and $65 \%$ of such cases develop during the first 2 years of life ${ }^{1,2}$. IM exhibits characteristic histopathological features, biphasic growth pattern, and immunohistochemical findings. Neoplastic cells in IM often express both $\alpha$-smooth muscle actin and calponin; however, CD34 in not usually expressed ${ }^{1}$. Focal positivity of CD34 has been reported ${ }^{3}$, and neoplastic cells exhibited diffuse expression of CD34 in several cases of $\mathrm{IM}^{4-6}$. Herein, we report a case of IM in a newborn with partially CD34-positive neoplastic cells.

\section{Case Report}

The patient was a 1-day-old boy born by Caesarean section at 38 weeks' gestation. He presented with a tumor on his right lower back, which had not been noted at birth. Physical examination revealed an elastic, hard, redto-slightly-yellowish tumor that was $11 \mathrm{~mm}$ in diameter (Fig. 1). Ultrasonographic examination showed a multilocular mass with a hypoechoic center surrounded by an isoechoic rim (Fig. 2). The differential diagnosis included hemangioma, leiomyoma, neurofibroma, and xanthoma. At age 8 days, the tumor was completely excised for di- agnosis.

Histological examination at a low-power view revealed multinodular proliferation of two different components, which reflected basophilic and eosinophilic regions in the dermis. Necrosis was observed in the lower dermis (Fig. 3a). The basophilic region contained a proliferation of small, round cells that were tightly packed and uniform and had pale oval nuclei (Fig. 3b). The area of eosinophilic staining contained richly cellular, interlacing fascicles of spindle cells with features of myofibroblasts (Fig. 3c). In the lower dermis, the lesion exhibited biphasic features, namely, a peripheral zone of spindle-shaped cells and a central portion with round cells. Some areas showed a hemangiopericytoma-like pattern, with multiple staghorn-like vascular spaces (Fig. 3d). There was no nuclear or cellular atypia. Immunohistochemical staining of neoplastic cells was positive for vimentin in both areas. $\alpha$-Smooth muscle actin ( $\alpha$-SMA) was strongly positive in the spindle cell area and weakly positive in the area of the small round cells (Fig. 4a). CD34 was positive in the area of the small round cells and endothelial cells but not in the myofibroblast-like areas (Fig. 4b, c). CD31 was detected in endothelial cells, which helped to highlight vessels, but was negative in the small round cells. Desmin, h-caldesmon, S-100 protein, and factor VIIIrelated antigen were all negative in the lesion. Mitotic ac-

Correspondence to Azusa Ogita, Department of Dermatology and Dermatopathology, Nippon Medical School Musashi Kosugi

Hospital, 1-396 Kosugi-cho, Nakahara-ku, Kawasaki, Kanagawa 211-8533, Japan

E-mail: azu@nms.ac.jp

https://doi.org/10.1272/jnms.JNMS.2020_87-609

Journal Website (https://www.nms.ac.jp/sh/jnms/) 


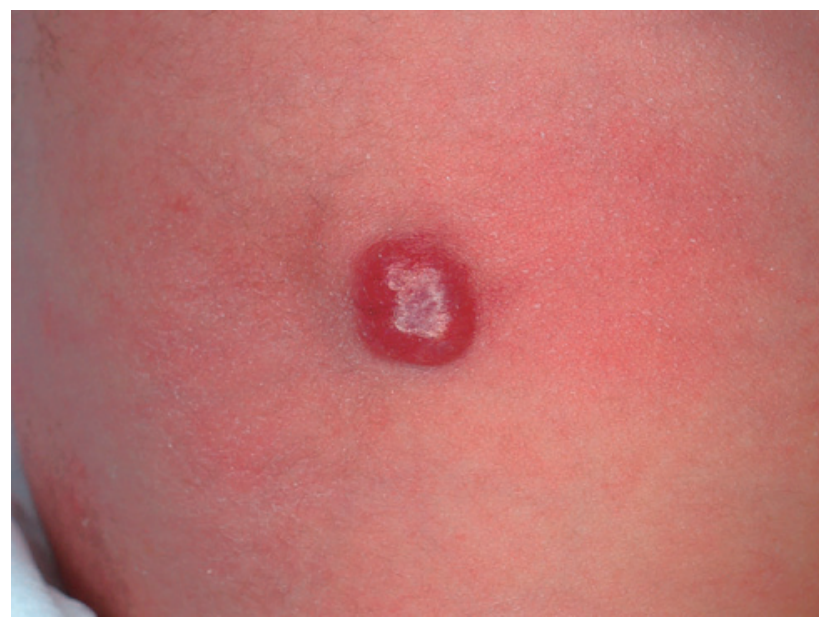

Fig. 1 Clinical findings of the present patient. The tumor was noted on the patient's right lower back.

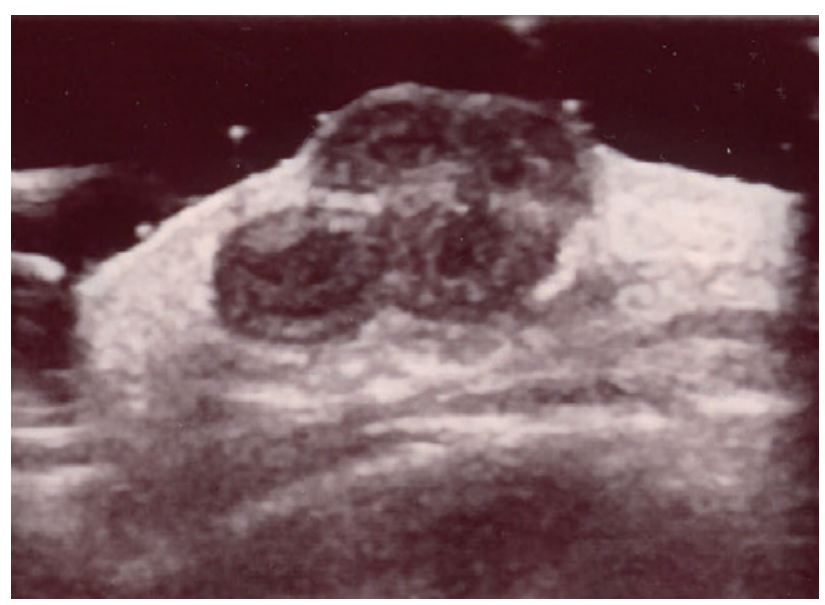

Fig. 2 Ultrasound image of the tumor shows a multilocular mass with a hypoechoic center surrounded by an isoechoic rim

tivity was low, and atypical mitosis was absent.

On the basis of these findings, the ultimate diagnosis was IM. Visceral involvement was absent. No local recurrence or other cutaneous lesions have been observed at 2 years after resection.

\section{Discussion}

IM is classified by clinical subgroup as solitary IM (approximately $70 \%$ of IM cases ${ }^{7}$; lesions located deep in soft tissues or in skin or subcutaneous tissue, predominantly in males $\left.{ }^{7}\right)$, multiple IM without visceral involvement, and multiple IM with visceral involvement. IM with visceral involvement is usually fatal. In approximately $30 \%$ of IM cases, lesions are multicentric and are present not only in skin and soft tissues but also in bone, lung, heart, and, most frequently, the gastrointestinal $\operatorname{tract}^{23}$.
On ultrasonographic examination, the present lesion exhibited a biphasic pattern, that is, a hypoechoic center surrounded by an isoechoic rim. Necrosis and proliferation of small, round cells appeared as a hypoechoic region, whereas, the area of spindle cells appeared isoechoic. Although few reports have described the ultrasound features of IM, the ultrasound appearance of IM appears to vary. The most common feature on ultrasound is a mass with an anechoic center ${ }^{8}$. The present lesion had a hypoechoic center, which is consistent with previously reported ultrasound features of IM.

The characteristic histological feature of IM is a biphasic growth pattern. The lesions consist of nodular dermal aggregates of spindle cells arranged in fascicles and an area of small, round cells surrounding thin-walled vessels with a hemangiopericytoma-like pattern ${ }^{1-3,7}$. The spindle cells are myofibroblastic cells, but the round cells are more primitive. These characteristic features indicated a diagnosis of IM in the present case.

As mentioned above, most case reports and textbooks state that neoplastic IM cells do not express CD34, although several patients with CD34-positive neoplastic cells have been reported ${ }^{1,4-6}$. CD34 is a glycosylated transmembrane protein that was initially characterized as a marker for hematopoietic stem cells and endothelial cells. A diverse group of neoplasms are reactive with anti-CD 34 antibodies, including solitary fibrous tumors, gastrointestinal stromal tumors, spindle cell lipomas, dermatofibrosarcoma protuberans, epithelioid sarcomas, myofibroblastomas, and neural tumors. However, the significance of CD34 positivity for differentiating neoplastic cells in those tumors is unclear.

IM and infantile hemangiopericytoma (IH) are different stages of maturation in a single group of myofibroblastic lesions of infancy, as noted by Mentzel et al. ${ }^{9}$ in their clinicopathological study. In the WHO classification of soft tissue tumors, $\mathrm{IH}$ is included in the spectrum of myopericytoma, myofibroma, and angioleiomyoma ${ }^{3}$. Elsewhere, $\mathrm{IH}$ is considered an infantile form of solitary fibrous tumor, with neoplastic cells that express CD $34^{10}$. If an IM includes an IH component, neoplastic cells in such areas may express CD34. In our patient, CD34 expression was observed only in small, round cells, distinct from cells with myofibroblastic differentiation, and some of those cells exhibited a hemangiopericytoma-like pattern. Those CD34-positive cells did not express CD31 or factor VIII-related antigen in our patient. Therefore, these cells did not differentiate toward endothelial cells. Normal hemangiopericytes do not express CD34 but do express $\alpha$ - 

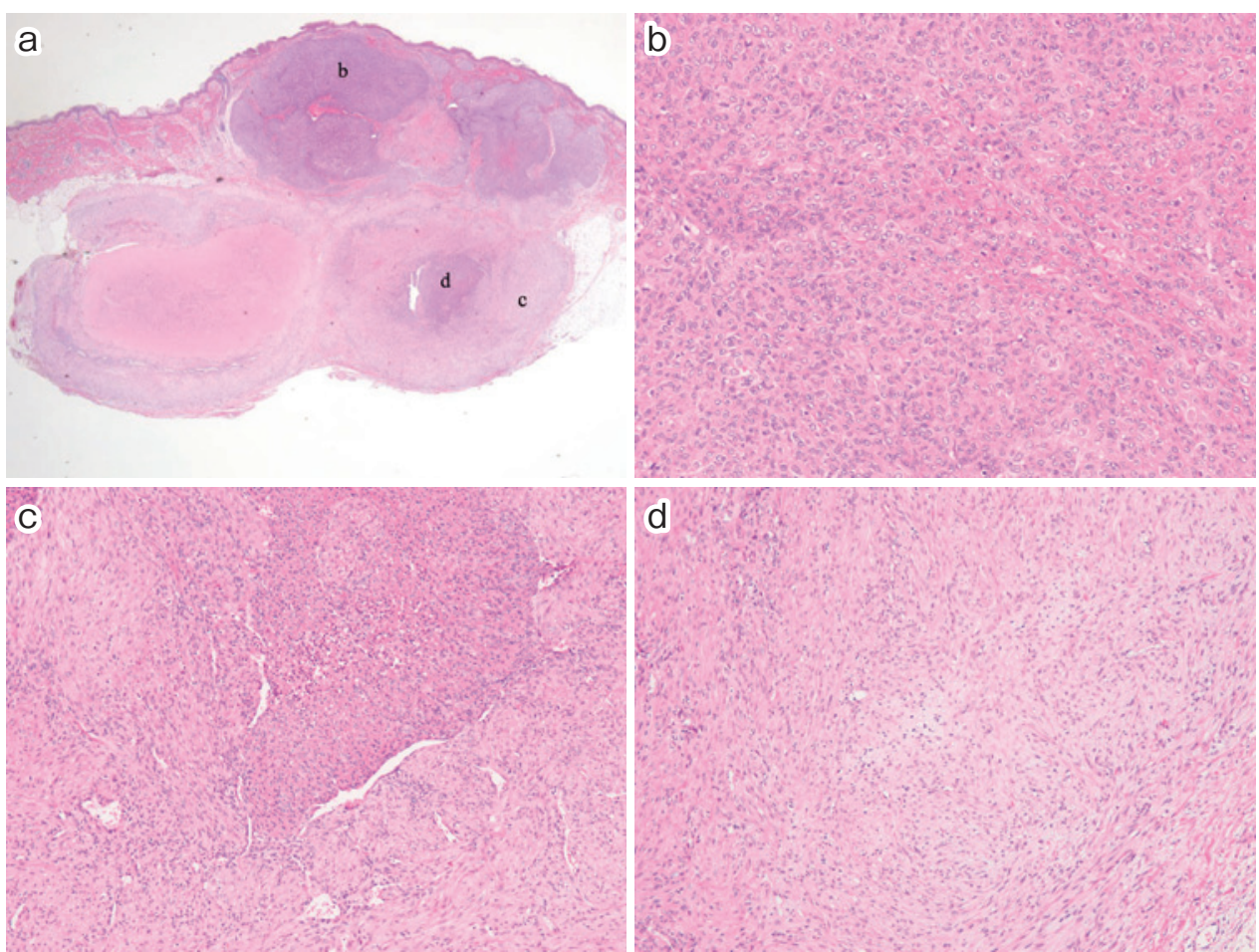

Fig. 3 Histopathological findings

a. A lesion showing multinodular proliferation of two separate components, which reflect the basophilic and eosinophilic regions.

b. The basophilic region exhibits proliferation of tightly packed, uniform, small, round cells with pale oval nuclei.

c. The eosinophilic region exhibits richly cellular, interlacing fascicles of spindle cells.

d. A hemangiopericytoma-like pattern with multiple staghorn-like vascular spaces.
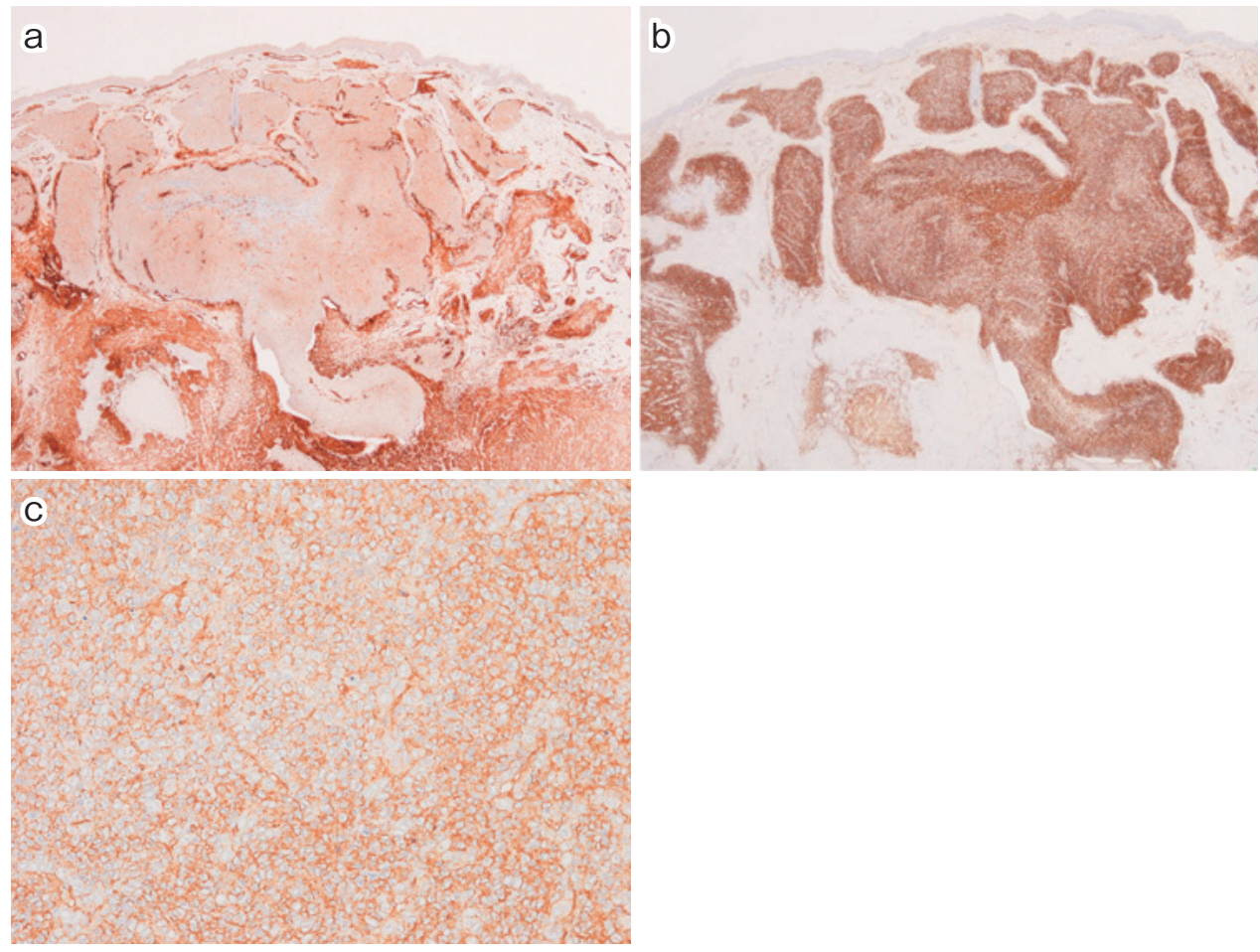

Fig. 4 Immunohistochemical findings

a. HE staining of eosinophils shows $\alpha$-smooth muscle actin expression.

b. The basophilic region and hemangiopericytoma-like area exhibits CD34-positive staining.

c. High-power view of CD34-positive neoplastic cells. 
SMA. However, neoplastic cells in most tumors with a hemangiopericytoma-like pattern, such as solitary fibrous tumors, express CD34 but not often $\alpha$-SMA. The reason for this discrepancy is unknown, but differentiated neoplastic cells with a hemangiopericytoma-like pattern may not be hemangiopericytes.

IM is mostly composed of neoplastic cells with myofibroblastic differentiation and $\alpha$-SMA positivity; however, the present IM appeared to comprise cells with myofibroblastic differentiation and more-primitive CD34-positive cells. Other reports did not provide a detailed description of CD34-positive neoplastic cells in $\mathrm{IM}^{4-6}$; only diffuse positivity of neoplastic cells was noted. Most of them might express both CD34 and $\alpha$-SMA. In those cases, neoplastic cells exhibit intermediate differentiation between myofibroblastic cells and more-primitive cells. From this perspective, our case is unique, because these two types of cells were clearly differentiated immunohistochemically.

The present findings suggest that although neoplastic cells in most IM cases differentiate towards myofibroblasts, in rare instances, differentiation is more primitive and results in mesenchymal cells, but not myofibroblasts, that express CD34, with or without $\alpha$-SMA. Neoplastic cells in IM rarely express CD34; however, IM should not be excluded even when tumor cells are CD34-positive.

\section{Conflict of Interest: No Conflict of Interest}

\section{References}

1. Agaimy A, Michal M, Wick MR. Myofibroma and myofibromatosis. In: Elder DE, Massi D, Scolyer RA, Willemze $\mathrm{R}$, editors. WHO classification of skin tumours. $4^{\text {th }}$ edn: IARC press; 2018. p. 322-3.

2. Oudjik L, den Bakker MA, Hop WC, et al. Solitary, multi- focal and generalized myofibromas: clinicopathological and immunohistochemical features of 114 cases. Histopathology. 2012;60:E1-11.

3. Mentzel T, Bridge JA. Myopericytoma including myofibroma. In: Fletcher CDM, Bridge JA, Hogendoorn PCW, Mertens F, editors. WHO classification of tumours of soft tissue and bone. $4^{\text {th }}$ edn: IARC press; 2013. p. 118-20.

4. Ichihashi K, Takenaka H, Asai J, et al. Infantile myofibromatosis of the scrotum. Eur J Dermatol. 2008;18:82-3.

5. Short M, Dramis A, Ramani P, et al. Mediastinal and pulmonary infantile myofibromatosis: an unusual surgical presentation. J Pediatr Surg. 2008;43:e29-31.

6. Kiyohara T, Maruta N, Iino S, Ido H, Tokuriki A, Hasegawa M. CD34-positive infantile myofibroma: Case report and review of hemagiopericytoma-like pattern tumors. J Dermatol. 2016;43:1088-91.

7. Patterson JW. Infantile myofibromatosis. Tumors and tumor-like proliferations of fibrous and related tissues. In: Patterson JW, editor. Weedon's skin pathology. $4^{\text {th }}$ edn: Elsevier; 2016. p. 983-4.

8. Koujok K, Ruiz RE, Hernandez RJ. Myofibromatosis; imaging characteristics. Pediatr Radiol. 2005;35:374-80.

9. Mentzel T, Calonje E, Nascimento AG, et al. Infantile hemangiopericytoma versus infantile myofibromatosis. Study of a series suggesting a continuous spectrum of infantile myofibroblastic lesions. Am J Surg Pathol. 1994;18: 922-30.

10. Goldblum JR, Folpe AL, Weiss SW. Infantile hemangiopericytoma. In: Goldblum JR, Folpe AL, Weiss SW, editors. Enzinger \& Weiss's soft tissue tumors. $6^{\text {th }}$ edn: Elsevier Saunders; 2014. p. 1017-8.

(Received, May 7, 2020)

(Accepted, June 19, 2020)

(J-STAGE Advance Publication, August 1, 2020)

Journal of Nippon Medical School has adopted the Creative Commons Attribution-NonCommercial-NoDerivatives 4.0 International License (https://creativecommons.org/licenses/by-nc-nd/4.0/) for this article. The Medical Association of Nippon Medical School remains the copyright holder of all articles. Anyone may download, reuse, copy, reprint, or distribute articles for non-profit purposes under this license, on condition that the authors of the articles are properly credited. 